\title{
Effects of a participatory community quality improvement strategy on improving household and provider health care behaviors and practices: a propensity score analysis
}

Tewabech Wereta ${ }^{1 *}$, Wuleta Betemariam¹, Ali Mehryar Karim, Nebreed Fesseha Zemichael ${ }^{1}$, Selamawit Dagnew ${ }^{1}$, Abera Wanboru' and Antoinette Bhattacharya ${ }^{2}$

\begin{abstract}
Background: Maternal and newborn health care intervention coverage has increased in many low-income countries over the last decade, yet poor quality of care remains a challenge, limiting health gains. The World Health Organization envisions community engagement as a critical component of health care delivery systems to ensure quality services, responsive to community needs. Aligned with this, a Participatory Community Quality Improvement (PCQI) strategy was introduced in Ethiopia, in 14 of 91 rural woredas (districts) where the Last Ten Kilometers Project (L10 K) Platform activities were supporting national Basic Emergency Obstetric and Newborn Care (BEmONC) strengthening strategies. This paper examines the effects of the PCQI strategy in improving maternal and newborn care behaviors, and providers' and households' practices.
\end{abstract}

Methods: PCQI engages communities in identifying barriers to access and quality of services, and developing, implementing and monitoring solutions. Thirty-four intervention kebeles (communities), which included the L10 K Platform, BEmONC, and PCQI, and 82 comparison kebeles, which included the L10 K Platform and BEmONC, were visited in December 2010-January 2011 and again 48 months later. Twelve women with children aged 0 to 11 months were interviewed in each kebele. Propensity score matching was used to estimate the program's average treatment effects (ATEs) on women's care seeking behavior, providers' service provision behavior and households' newborn care practices.

Results: The ATEs of PCQI were statistically significant $(p<0.05)$ for two care seeking behaviors - four or more antenatal care (ANC) visits and institutional deliveries at $14 \%(95 \% \mathrm{Cl}: 6,21)$ and $11 \%(95 \% \mathrm{Cl}: 4,17)$, respectively - and one service provision behavior - complete ANC at 17\% (95\% Cl: 11, 24). We found no evidence of an effect on remaining outcomes relating to household newborn care practices, and postnatal care performed by the provider.

\footnotetext{
* Correspondence: weretatewabech@gmail.com

${ }^{1}$ The Last Ten Kilometers Project (L10K) 2020, JSI Research and Training

Institute, Inc, Bole Sub-City, Kebele 03/05, Hs \# 2111, Addis Ababa, Ethiopia

Full list of author information is available at the end of the article
}

(c) The Author(s). 2018 Open Access This article is distributed under the terms of the Creative Commons Attribution 4.0 International License (http://creativecommons.org/licenses/by/4.0/), which permits unrestricted use, distribution, and reproduction in any medium, provided you give appropriate credit to the original author(s) and the source, provide a link to the Creative Commons license, and indicate if changes were made. The Creative Commons Public Domain Dedication waiver (http://creativecommons.org/publicdomain/zero/1.0/) applies to the data made available in this article, unless otherwise stated. 
(Continued from previous page)

Conclusions: National BEmONC strengthening and government initiatives to improve access and quality of maternal and newborn health services, together with L10 K Platform activities, appeared to work better for some care practices where communities were engaged in the PCQI strategy. Additional research with more robust measure of impact and cost-effectiveness analysis would be useful to establish effectiveness for a wider set of outcomes.

Keywords: Maternal, Newborn, Quality improvement, Community engagement,

\section{Background}

Maternal and neonatal mortality have reduced considerably in the last decades, but low and middle-income countries continue to bear the highest burden of deaths among women around the time of childbirth and among newborns [1]. Of the 830 women who died each day in 2015 due to complications related to pregnancy and childbirth, the majority were in Sub-Saharan Africa and Southern Asia [2]. Although maternal deaths declined by $44 \%$ between 1990 and 2015, the maternal mortality ratio in many countries remains unacceptably high with disparities among and within countries [1].

Of the estimated 5.9 million child deaths in 2015, 40\% occurred during the neonatal period. The decline in neonatal mortality in 1990-2015 has been slower than that of post-neonatal under-five mortality (1-59 months) in most low and middle-income countries [3].

Sustainable Development Goal 3 aims to reduce the global maternal mortality ratio to less than 70 per 100,000 live births by 2030 and the newborn mortality rate to as low as 12 per 1,000 live births [4]. Achieving these ambitious targets will require universal coverage of high quality and high impact maternal and newborn health interventions $[5,6]$.

Evidence from the Millennium Development Goal era indicates that although many countries were able to increase the coverage of a number of high impact interventions (e.g. skilled birth attendance), poor quality of care remains a concern limiting health gains, as it reduces access to care and its effectiveness [6-10]. Thus, implementing high quality interventions during the intrapartum and immediate postpartum period - to prevent the majority of the maternal and newborn deaths [5] - is among the most urgent priorities of the global action agendas $[11,12]$.

Among the strategies essential for achieving improvements in maternal and newborn health, as reiterated by various international declarations and statements, is the engagement of households and communities in health interventions. Working with individuals, families and communities is a critical link to ensure the recommended continuum of care throughout pregnancy, childbirth and the postpartum period. Given the growing recognition that health cannot be assured solely by actors in the health sector, engaging communities is also key to improving and maintaining interventions that advance health gains [13-16].

People are more likely to use and respond positively to health services if they have been involved in decisions about how these services are delivered. They are willing to contribute resources for health improvement and they would also be more likely to change behaviors that would help them take control over their own lives. Furthermore, community participation in setting health priorities, making decisions, and planning and implementing strategies helps to promote health and quality of service $[13,17,18]$.

Community engagement refers to efforts that promote dialogue, sharing of information and resources, and decision making between members of the community and the health department [19]. It improves mutual understanding and increases awareness of the realities, perspectives and conditions of the other party. It enables communities to effectively identify problems and root causes, understand context, plan and manage resources, solve problems, and use data to monitor progress and make decisions. This participatory approach helps to raise awareness within the community and to stimulate social support and participation in problem-solving $[13,17,18,20]$.

Several studies report that engaging communities improves care seeking behavior, including increased antenatal care (ANC) visits and institutional deliveries [20-22]. A systematic review of the effects of community participation on improved maternal and newborn health that included 12 countries with multiple interventions studies in different parts of the same country was conducted by Marston et al. [23]. Studies in Nepal, India, Uganda, Kenya and Eritrea reported that engaging communities had a largely positive impact in terms of increased use of ANC services, facility deliveries, reduced neonatal mortality and improved accountability of health care providers. Moreover, engaging communities in health programs can lead to improvements in client confidence, trust-building, credibility and, subsequently, to improved perceptions of health care quality. This may result in increased health care seeking behavior and uptake and quality of services, ultimately improving health outcomes $[19,24]$. Community engagement can also create accountability and promote a sense of ownership, acceptability of health policies by community members and sustainability of quality improvement interventions $[23,24]$. 
Nearly 40 years after the Declaration of Alma-Ata, which stated equity, social justice and community participation as key to achieving primary health care, the application of community engagement in improving the delivery of health care remains sporadic and poorly documented [15].

While the role of community engagement in improving maternal and newborn health services has been demonstrated, the variation of community engagement approaches and the intensity of implementation make it difficult to determine which of the strategies were most effective and compare the different strategies [25-27]. Further, because of these variations in community engagement approaches and because community engagement is usually implemented within a strategy with multiple components, some studies have been unable to directly identify the link between community participation and improved health outcomes [26]. Some have argued that the relationship between community engagement and health outcomes is not direct as there are other factors that positively influence the relationship, and others note that the success community engagement depends on the context and cannot be replicated on a larger scale [19, 27].

The objective of this study was to assess the contribution of a Participatory Community Quality Improvement (PCQI) strategy on improving household and provider maternal and newborn care behaviors and practices in Ethiopia. This paper is the third in a series of four papers investigating community-based strategies to improve reproductive, maternal, newborn, and child health in the country. The other three papers studied the Women's Development Army (WDA), Community-Based Data for Decision-Making (CBDDM) and the Family Conversation strategies [28].

\section{Methods}

\section{Study setting}

Ethiopia's maternal mortality ratio and newborn mortality rate are among the highest in the world at 421 per 100,000 live births and 29 per 1,000 live births, respectively, according to the 2016 Ethiopia Demographic and Health Survey estimate [29]. Although access to maternal and newborn health services has improved, the quality of care remains an immense challenge and often the services do not respond fully to community needs [30, 31].

In 2015, the Government of Ethiopia made a commitment towards achieving the health-related Sustainable Development Goals by launching its Health Sector Transformation Plan, under which it set ambitious targets to reduce the maternal mortality ratio to 199 per 100,000 live births and the neonatal mortality rate to 10 per 1,000 live births by 2020 [7]. Moreover, the Health Sector Transformation Plan cited universal coverage of high quality maternal and newborn health services which respond to the community's needs and are respectful to clients, among its top priorities.

The Government of Ethiopia launched a number of programs to increase access to quality maternal and child health care. For example, it introduced its flagship Health Extension Program in 2004 to improve primary health care at community level and transfer ownership of and responsibility for improving health to communities and individual households through a package of promotive, preventive and basic curative services aimed at women and children [31].

The primary level of healthcare, as articulated in the Health Sector Transformation Plan, is the primary health care unit which comprises four or five health posts and one health center, which together with three or four other primary health care units is served by a primary hospital. The primary health care unit is appointed to serve as the administrative, technical and supportive supervision link to their health posts [7]. Each health post is staffed by two Health Extension Workers (HEWs) and, to extend their reach in mobilizing communities and households, each kebele (community) includes a network of women volunteers who form the WDA, also known as Health Development Army.

Since 2008, The Last Ten Kilometers Project (L10 K) has been working to improve coverage of effective reproductive, maternal, newborn and child health services, and to strengthen the skills of HEWs in 115 of 408 woredas (districts) across four regions of Ethiopia, covering about $19 \%$ of the country's population: Amhara, Oromia, Tigray, and Southern Nations, Nationalities, and Peoples' Region. The L10 K Platform in the 115 woredas included CBDDM, a surveillance system of households to ensure continuum of care for reproductive, maternal, newborn and child health services; Family Conversations, a forum conducted at the house of a pregnant woman with her family members during the antenatal period, to reinforce birth preparedness; and Birth Notification to ensure early postnatal care. (For details on the Platform please see Additional files 1-3 for the first paper in this supplement and two of the other papers in this supplement on the CBDDM and Family Conversations strategies [28, 32, 33]).

In October 2012, the L10 K Project introduced a program in 91 woredas to improve basic emergency obstetric and newborn care (BEmONC) through training, mentoring, provision of equipment and supplies, and addressing barriers for improved infection prevention practices. The L10 K Project complemented Ethiopian government initiatives to improve maternal and newborn health outcomes, which included infrastructure expansion of primary health care units, strengthening the referral system, procurement of ambulances to provide 
free transport to laboring women, maternal death surveillance and response, training of health care providers in basic maternal and neonatal care, and fee waivers and exemptions for maternal and child health care services [34].

To improve demand and quality of these services, the PCQI strategy was implemented from October 2012 in all 93 intervention kebeles communities) across 14 woredas where BEmONC was also initiated. The primary focus of PCQI in the first 18 months was on maternal care in two PCQI cycles (cycles described below); this was subsequently extended to include newborn care in the third cycle, for 6 months.

The PCQI strategy aimed to achieve its goal by facilitating community involvement in defining, implementing and monitoring the quality improvement process. Figure 1 shows a conceptual framework for the strategy. Increasing access and quality of ANC, delivery and perinatal outcomes began with an understanding of the barriers to quality care from provider and community perspectives. By strengthening communication processes on issues related to the quality of maternal and neonatal care, it was expected that enhanced interactions between the communities, HEWs, health care providers and woreda health offices would lead to recognition of a shared responsibility in improving maternal and newborn care behaviors and practices.

PCQI involves a seven step cyclical process to achieve outcomes, as shown in Fig. 2.; 1) Selecting the primary care unit and holding a launching workshop with key stakeholders to build consensus. 2) Identifying and meeting community representatives (pregnant women, husbands, mother in laws; religious leaders and WDA members). 3) Explore quality meeting: conducting meetings with community representatives and biannual meetings at the facility level to identify major barriers to accessing services and gaps in service provision. 4) Bridging the gap workshops bringing community representatives and health workers from the health center together, to present their own perspective on barriers and service gaps (e.g. low care seeking behaviour; a health post not providing $24 \mathrm{~h}$ services because the HEWs live outside the kebele; communities unable to reach the health center due to poor roads and lack of transport; disruption of drugs and basic supplies; little confidence in giving birth at a health facility; and low levels of trust in the community). 5) Development of strategies and a joint action plan to address these barriers and gaps. 6)

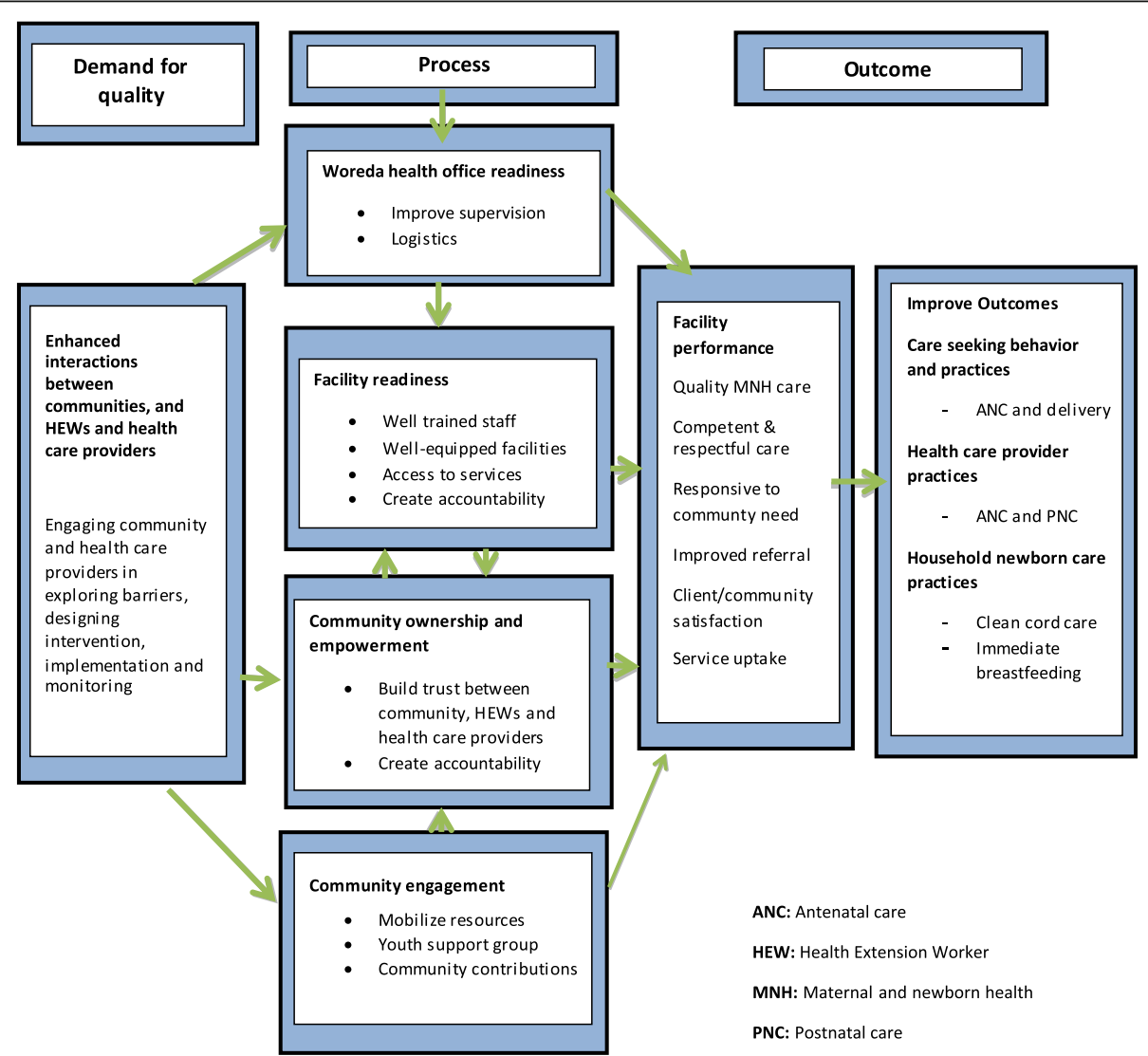

Fig. 1 Conceptual framework of the PCQI strategy 


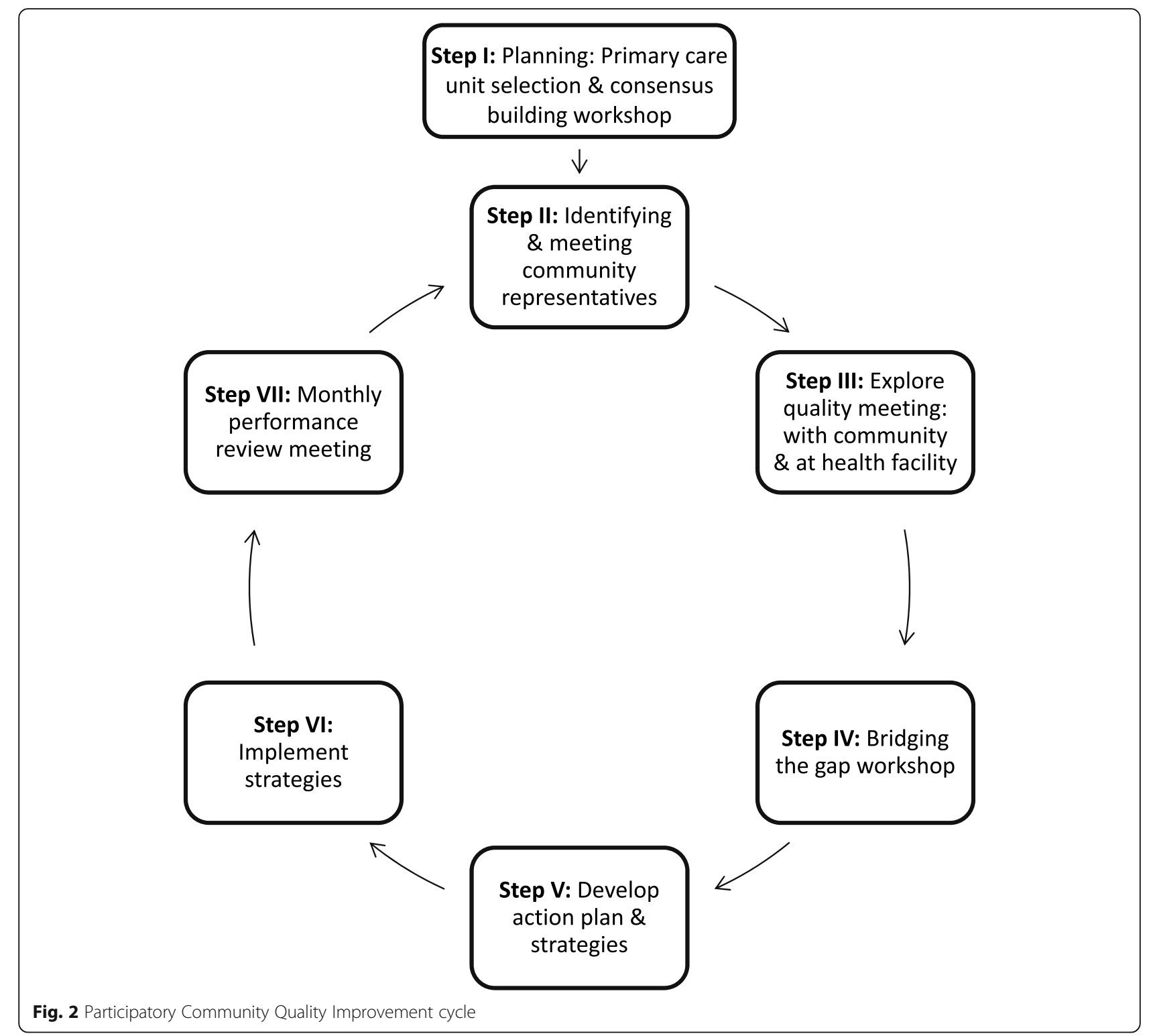

Implementation of the identified strategies (e.g. building HEW residences to enable HEWs to provide 24 h services; outreach sites; maintaining roads to facilitate transportation of pregnant mothers; preparing local stretchers for transporting women in labor and organizing youth groups to carry women in labor; supporting HEWs to inform the community about their schedule regularly; arranging a labor ward tour for women in their third trimester; training WDA members on the proper use of the family health card; promoting timely provision of drugs and supplies by woreda health offices). 7) Monthly review meetings of the performance of each strategy.

\section{Study design}

This study was nested in a broader program evaluation for the L10 K Project and drew from the before-and-after household surveys conducted in January 2010-February 2011 and January 2014-February 2015, comparing areas with both PCQI and BEmONC strengthening in addition to the L10 K Platform, to the areas with BEmONC strengthening with the L10 K Platform alone. As indicated earlier, the L10 K Platform included the CBDDM and Family Conversation strategies and Birth Notification. The endline household survey was conducted after 26 months of PCQI intervention activities.

\section{Sample size and study participants}

The sample size for the PCQI intervention area was based on precision and not based on detecting effect estimates of the PCQI strategy. The parameters of the sample size estimation were: $50 \%$ expected prevalence, $95 \%$ confidence interval $(\mathrm{CI})$ with \pm 6 percentage-points 
precision, 1.5 cluster survey design effect, with number of respondents per cluster set at 12 . Thus, 34 primary sampling units were needed to obtain the sample size for the intervention area. The study participants were women of reproductive age who had a live birth in the 12 months before the survey.

About 324 kebeles from the L10 $\mathrm{K}$ intervention areas were visited during both the survey periods of the broader evaluation (Table A2 in Additional file 1 for the first paper in this supplement [28]). These included 34 required kebeles from the PCQI areas and 82 kebeles that met the comparison group criteria. Thus, the sample sizes for propensity score matching (PSM) were 408 women from the intervention area and 990 women from the comparison area. In few cases the interviewers mistakenly interviewed more than 12 women from a kebele which resulted in six more women than the expected $984(=12$ X 82) respondents in the comparison areas.

\section{Data collection}

The broader L10 K evaluation was a two-stage cluster survey, stratified by administrative regions and the L10 K Project strategy (including PCQI). Kebeles were selected as primary sampling units (clusters) with the probability proportionate to its population size. At the second stage, the sampling strategy described by Lemeshow and Robinson was used to select the household with the target respondents [35]. Accordingly, the first household was selected randomly from the middle of the kebele and then every fifth household was visited, moving away from the middle, and if the household had women with children aged 0 to 11 months old they were interviewed, after seeking their consent. Twelve women were interviewed from each kebele to obtain information on their socio-demographic background and the maternal and newborn health care behavior and practices associated with their most recent pregnancy and childbirth. The health post of the sampled kebeles was visited, the HEWs interviewed, and the health post records reviewed to obtain information on HEW to population ratio (Additional files 1-3 for the first paper in this supplement [28]).

\section{Outcomes of interest}

The outcome indicators of interest were household and provider maternal and newborn health care behaviors and practices associated with the most recent childbirths among women with children aged 0 to 11 months. These were measured by the household survey. The definitions of the indicators are shown in Table 1.

\section{Independent variables}

The independent variables of interest were the indicator variables for each study arm and survey period and the respondent's age, education, marital status, parity, religion, household wealth, distance of the respondent's household to the nearest health facility, administrative region and HEW density of the sampled kebele.

The wealth index score was constructed for each household using the principal component analysis of household possessions (electricity, watch, radio, television, mobile phone, telephone, refrigerator, table, chair, bed, electric stove and kerosene lamp), and household characteristics (type of latrine and water source). The index was created among all respondents in the larger dataset from which the data for this study were extracted. The households of the larger survey were ranked according to the wealth score and then divided into five quintiles [36]. The WDA density in a kebele was the ratio between the total number of households and the number of active WDA team leaders in that kebele. Active WDA team leaders were those who had met with a HEW and discussed Health Extension Program issues during the 3 months preceding the survey.

\section{Statistical analysis}

First, we compared individual, household and kebele-level sample characteristics measured in the follow-up survey across study arms using Pearson's chi-squared statistics adjusted for cluster survey design effects. Similar statistical tests were done to 1) compare the outcome variables between the study arms during the baseline and the follow-up surveys; and 2) to assess statistically significant changes in the outcome variables during the observation period within each of the study arms. Stata 14.2 was used for the statistical analysis conducted for this study [37].

Propensity score matching was used to identify comparison individuals that were similar to those in the intervention area at follow-up, in terms of the background characteristics of the respondents, including kebele level estimates of the outcome of interest at baseline. Propensity scores are the probabilities of participation in the intervention and were estimated using logit models for each of the seven outcomes of interest, using the baseline kebele-level estimate of the given outcome as a covariate along with the background characteristics of the respondents in each case. We assessed average treatment effects (ATEs) of PCQI on the outcomes of interest using Stata's 'teffects psmatch' procedure [38, 39]. The method imputes missing potential outcomes for each participant by using an average of the outcomes of similar participants that receive the other treatment level. The ATE was then calculated by taking the average of the difference between the observed and potential outcomes for each participant.

To assess the adequacy of the matching, we assessed the balance of covariates across study arms after 
Table 1 Definition of maternal and newborn health care indicators

\begin{tabular}{ll}
\hline Indicator & Definition \\
\hline $\begin{array}{l}\text { Women's care seeking behavior } \\
\text { Received four or more }\end{array}$ & $\begin{array}{l}\text { The percentage of women who went } \\
\text { to a health facility for antenatal care } \\
\text { at least four times during last } \\
\text { pregnancy }\end{array}$ \\
Delivery at health facility & $\begin{array}{l}\text { The percentage of women who had } \\
\text { their last childbirth at a health facility } \\
\text { with skilled birth attendants }\end{array}$
\end{tabular}

Providers' service provision behavior

Complete antenatal care The percentage of women who had their blood pressure measured, blood tested and urine tested during last pregnancy

Early postnatal care

The percentage of women who were visited by HEWs at home for postnata care or newborn care within $48 \mathrm{~h}$ of last childbirth (among facility and home births. Women discharged from health facilities 6 hours after delivery)

Women's care seeking and providers' service provision behavior

Neonatal tetanus protected The percentage of women whose last childbirth childbirth was protected against neonatal tetanus

Households' newborn care practices

Practiced clean cord care of their newborn

Immediate initiation of breastfeeding
The percentage who were not assisted by skilled birth attendants, but who cut the umbilical cord of their last newborn with a sterile instrument, tied the cut end of the cord with sterile thread and applied nothing to the cut end of the umbilical cord

The percentage of women who were not assisted by skilled birth attendants, but who initiated breastfeeding their newborn immediately after birth

matching. Balance was considered adequate if the standardized differences of the covariates between the study arms were less than $10 \%$ after matching [40]. A minimum of one-to-one match per participant was considered adequate if the balancing property was satisfied. If the one-to-one match did not satisfy the balancing property, then the minimum number of matches per participant was incrementally increased until the balancing property was satisfied [40]. The method selected an extra match per participant if the propensity score was tied. ATEs are presented from propensity scored matched models that satisfied the balancing property.

\section{Results}

Table 2 indicates that compared with the comparison areas, the respondents from the intervention areas were more likely $(p<0.05)$ to have higher education, be from higher wealth quintiles, and live closer to a health facility.
In terms of outcomes, coverage levels were generally higher in intervention groups than in comparison groups at baseline, with differences being statistically significant for complete ANC and institutional deliveries $(p<0.05$, Table 3). In Table 3, comparing the baseline survey estimates with the follow-up survey estimates for the outcomes of interest, we can see that there were substantial improvements $(p<0.05)$ in all outcomes except early postnatal care (PNC) and clean cord care in both the study arms ( $p$-values are not shown in Table 3$)$. The clean cord care actually significantly declined $(p<.05)$ between the survey periods in both the study arms.

The ATEs of PCQI on household and provider maternal and newborn health care behaviors and practices from the PSM models are provided in Table 4. The PSM models were balanced for differences in the co-variates between the study arms (shown in Table 2) and the differences of the outcome between the two study arms at baseline (shown in Table 3). The standardized differences in the co-variates between intervention and comparison group respondents before and after matching for the seven PSM models are given in an additional table (Additional file 1 for this paper). The ATEs of PCQI on maternal and newborn behavior and practices were found to be significantly higher for three of the monitored outcomes in intervention sites compared with comparison sites; $14 \%$ and $11 \%$ points higher for women's care seeking behavior, for four or more ANC visits and for institutional deliveries respectively, and $17 \%$ higher for health care providers provision of complete ANC $(p<0.05)$ (Table 4). There was no effect on the other outcomes.

\section{Discussion}

This study found that community engagement in quality improvement for maternal and newborn health care services alongside the L10 K Platform activities and national $\mathrm{BEmONC}$ strengthening initiatives was associated with an increase in the coverage of ANC visits, complete ANC and institutional deliveries. Furthermore, there were several government initiatives such as skills training for health care providers, introduction of free ambulance services and maternal death surveillance targeted to improve access and quality of maternal health services in both the study arms and it appears that these initiatives work better where communities engage in the PCQI strategy.

These findings support the hypothesis that engagement of communities in quality improvement could promote women's health care seeking and improve health care providers' behavior in relation to quality of care. This is consistent with a study in Ethiopia which found that enhanced interactions among health workers and women and their families improved coverage and quality 
Table 2 Characteristics of the complete sample by study arm during the follow-up survey (2014-15)

\begin{tabular}{|c|c|c|c|c|c|c|}
\hline \multirow[t]{2}{*}{ Sample characteristics } & & \multicolumn{2}{|c|}{ Comparison } & \multicolumn{2}{|c|}{ Intervention } & \multirow{2}{*}{$\begin{array}{l}p- \\
\text { value }\end{array}$} \\
\hline & & $\%$ & $\mathrm{~N}$ & $\%$ & $\mathrm{~N}$ & \\
\hline \multirow[t]{4}{*}{ Age group } & $15-19$ & 8 & 74 & 9 & 38 & 0.230 \\
\hline & $20-24$ & 26 & 254 & 31 & 126 & \\
\hline & $25-34$ & 51 & 501 & 46 & 186 & \\
\hline & $35-49$ & 16 & 160 & 15 & 59 & \\
\hline \multirow[t]{3}{*}{ Education } & Cannot read & 59 & 584 & 47 & 193 & 0.009 \\
\hline & Primary & 23 & 224 & 24 & 100 & \\
\hline & Higher & 18 & 182 & 28 & 116 & \\
\hline \multirow[t]{2}{*}{ Marital status } & Other & 2 & 17 & 3 & 11 & 0.247 \\
\hline & In union & 98 & 973 & 97 & 397 & \\
\hline \multirow[t]{4}{*}{ Number of children } & 1 & 26 & 253 & 31 & 124 & 0.104 \\
\hline & 2 & 15 & 150 & 19 & 79 & \\
\hline & 3 & 16 & 155 & 15 & 60 & \\
\hline & $4+$ & 44 & 431 & 35 & 144 & \\
\hline \multirow[t]{4}{*}{ Religion } & Orthodox & 52 & 519 & 57 & 233 & 0.835 \\
\hline & Protestant & 27 & 270 & 23 & 93 & \\
\hline & Muslim & 19 & 192 & 20 & 80 & \\
\hline & Other & 1 & 9 & 1 & 2 & \\
\hline \multirow[t]{5}{*}{ Wealth quintile } & Lowest & 18 & 182 & 17 & 71 & 0.020 \\
\hline & Second & 19 & 192 & 18 & 71 & \\
\hline & Middle & 23 & 223 & 12 & 50 & \\
\hline & Fourth & 23 & 228 & 24 & 96 & \\
\hline & Highest & 17 & 166 & 29 & 120 & \\
\hline \multirow[t]{3}{*}{ Distance to any health facility } & $<30 \min$ & 46 & 457 & 60 & 243 & 0.003 \\
\hline & 30 to $59 \mathrm{~min}$ & 37 & 361 & 32 & 129 & \\
\hline & $1+$ hours & 17 & 172 & 9 & 36 & \\
\hline \multirow[t]{4}{*}{ Region } & Tigray & 18 & 175 & 17 & 71 & 0.953 \\
\hline & Amhara & 25 & 250 & 29 & 117 & \\
\hline & Oromia & 24 & 241 & 20 & 81 & \\
\hline & SNNP & 33 & 324 & 34 & 140 & \\
\hline \multirow[t]{4}{*}{ HEW density (population per HEW in kebele) } & 2,499 & 41 & 408 & 26 & 107 & 0.120 \\
\hline & 2,500 to 3,499 & 22 & 215 & 42 & 171 & \\
\hline & 3,500 to 4,999 & 25 & 251 & 21 & 86 & \\
\hline & $5,000+$ & 12 & 115 & 11 & 44 & \\
\hline Total & & 100 & 990 & 100 & 408 & \\
\hline
\end{tabular}

HEW health extension worker, SNNP Southern Nations, Nationalities and Peoples

of maternal and newborn health services and outcomes [22].

It is also in line with the findings of a systematic review of effects of Community Participation on improving uptake of skilled care for maternal and newborn health which revealed community engagement increased uptake of ANC and institutional delivery in India, Nepal, Bangladesh, Uganda and Kenya [23]. Moreover, studies have showed that improvements in provider training, management practice, availability of equipment and supplies, communication with the community about the quality of care and cultural practices in relation to pregnancy and child birth increase care seeking for ANC, institutional delivery and the quality of those services [41, 42].

Along with L10 K-supported BEmONC activities and CBDDM, there were several government initiatives, such as staff training and maternal death surveillance, targeted to improve maternal services in both the study 
Table 3 Maternal and newborn care by study arm and survey period, complete sample

\begin{tabular}{|c|c|c|c|c|c|c|}
\hline & \multicolumn{3}{|l|}{ Baseline } & \multicolumn{3}{|l|}{ Follow-up } \\
\hline & $\begin{array}{l}\text { Comparison } \\
\%(\mathrm{~N}) \\
(95 \% \mathrm{Cl})\end{array}$ & $\begin{array}{l}\text { Intervention } \\
\%(\mathrm{~N}) \\
(95 \% \mathrm{Cl})\end{array}$ & $p$-value $(a)$ & $\begin{array}{l}\text { Comparison } \\
\%(\mathrm{~N}) \\
(95 \% \mathrm{Cl})\end{array}$ & $\begin{array}{l}\text { Intervention } \\
\%(\mathrm{~N}) \\
(95 \% \mathrm{Cl})\end{array}$ & $p$-value (a) \\
\hline \multirow[t]{2}{*}{ ANC 4+ } & 30 (983) & $35(408)$ & 0.360 & $51(990)$ & $61(408)$ & 0.014 \\
\hline & $(26,25)$ & $(26,43)$ & & $(46,55)$ & $(54,68)$ & \\
\hline \multirow[t]{2}{*}{ Complete ANC } & $10(983)$ & $18(408)$ & 0.007 & $52(990)$ & $74(408)$ & $<0.001$ \\
\hline & $(7,13)$ & $(12,23)$ & & $(46,58)$ & $(67,81)$ & \\
\hline \multirow[t]{2}{*}{ Neonatal tetanus protected birth } & $56(983)$ & $61(408)$ & 0.293 & 65 (990) & $72(408)$ & 0.063 \\
\hline & $(52,61)$ & $(54,68)$ & & $(60,69)$ & $(66,79)$ & \\
\hline \multirow[t]{2}{*}{ Delivery at health facility } & $9(983)$ & $20(408)$ & 0.001 & $53(990)$ & $69(408)$ & 0.007 \\
\hline & $(7,12)$ & $(13,26)$ & & $(47,60)$ & $(60,78)$ & \\
\hline \multirow[t]{2}{*}{ Early PNC } & $8(983)$ & $11(408)$ & 0.225 & $9(990)$ & $7(408)$ & 0.437 \\
\hline & $(6,11)$ & $(7,15)$ & & $(6,11)$ & $(4,10)$ & \\
\hline \multirow[t]{2}{*}{ Clean cord care } & $47(878)$ & $46(334)$ & 0.862 & 35 (436) & $28(131)$ & 0.223 \\
\hline & $(41,53)$ & $(38,54)$ & & $(28,42)$ & $(18,37)$ & \\
\hline \multirow[t]{2}{*}{ Immediately initiating breastfeeding } & $60(878)$ & $60(334)$ & 0.941 & $71(436)$ & $71(131)$ & 0.934 \\
\hline & $(54,65)$ & $(52,69)$ & & $(64,77)$ & $(57,86)$ & \\
\hline
\end{tabular}

(a) $\mathrm{p}$-values of the test of differences between study arms

ANC antenatal care, ANC 4+ received four or more antenatal care visits, PNC postnatal care

arms and it appears that these initiatives work better where communities engage in the PCQI strategy.

While the importance of addressing the needs of the supply side is undeniable, our study showed that the engagement of communities can play a significant role in enhancing health care seeking behaviors and practices and improving quality of care. Communities' engagement in planning, implementation and decision-making can enable them, together with health system staff, to address barriers to care seeking, demand high quality health and make health systems responsive to communities, ultimately contributing to improved maternal and newborn health.

During a qualitative process evaluation of the L10 K project, communities also described the benefits of community engagement in quality improvement as community empowerment or ownership, more respectful care and an improved relationship between HEWs and their community (McCutcheon JC, Gebrekirstos T. A community quality improvement approach to facilitate more respectful care for pregnant women and increase health worker-assisted deliveries in rural Ethiopia. [unpublished]).

There was no evidence of an intervention effect on household practices of neonatal care and provision of early postnatal care by health care providers. This might be explained by the fact that the PCQI strategy focused on maternal services during the first 18 months of implementation and only expanded its focus to neonatal care practices and postpartum care 8 months before the evaluation.

Table 4 Maternal and newborn health care outcomes and average treatment effects, matched sample

\begin{tabular}{|c|c|c|c|c|c|c|c|c|}
\hline & \multicolumn{2}{|c|}{ Control } & \multicolumn{2}{|c|}{ Intervention } & \multirow{2}{*}{$\begin{array}{l}\text { \# of } \\
\text { matched } \\
\text { (a) }\end{array}$} & \multicolumn{3}{|l|}{ ATE } \\
\hline & $\%$ & $(N)^{a}$ & $\%$ & $(N)^{a}$ & & \%-points & $95 \% \mathrm{Cl}$ & $p$-value \\
\hline ANC 4+ & 51.3 & (372) & 65.2 & (941) & $1-2$ & 13.9 & $(6.3,21.4)$ & $<0.001$ \\
\hline Complete ANC & 53.6 & (372) & 70.7 & (941) & $2-4$ & 17.1 & $(10.7,23.6)$ & $<0.001$ \\
\hline Neonatal tetanus protected birth & 69.9 & (373) & 69.6 & (941) & $1-3$ & -0.3 & $(-7.3,6.7)$ & 0.935 \\
\hline Institutional deliveries & 57.6 & (373) & 68.1 & (941) & $4-5$ & 10.5 & $(4.2,16.8)$ & 0.001 \\
\hline Early PNC & 9.2 & (373) & 8.5 & (941) & $2-3$ & -0.7 & $(-4.9,3.6)$ & 0.753 \\
\hline Clean cord care & 35.8 & (119) & 32.1 & $(415)$ & $3-4$ & -3.6 & $(-14.7,7.4)$ & 0.521 \\
\hline Immediate initiation of breastfeeding & 73.5 & (119) & 76.4 & (534) & $3-4$ & 2.8 & $(-4.7,10.6)$ & 0.468 \\
\hline
\end{tabular}

${ }^{a}$ Number of observation that was used for the PSM analysis

(a) Number of matches per participant for the PSM models

ANC antenatal care, ANC 4+ received four or more antenatal visits, ATE average treatment effect, PNC postnatal care, PSM propensity score matching 
The short duration of exposure did not allow the PCQI cycles for newborn care to be completed. Moreover, the maternal and newborn outcomes considered were associated with the most recent childbirths among women with children aged 0 to 11 months; as such, one-third of respondents during the follow-up survey were not exposed to the PCQI cycles on newborn care.

It should also be noted that household newborn health care practices are deep-rooted cultural habits, having been practiced for generations and with great meaning attached to them, such as washing a newborn immediately after delivery because it is believed babies are born dirty and have to be cleaned. Communities therefore, are usually not willing to let go of these cultural practices, thus, necessitating gradual changes in practicing essential newborn health care. This may also be true of maternal care practices; however, this study did not address these practices [43-45].

With regards to study methods, we observed that a number of the background characteristics, including the outcomes of interest, were significantly different between the intervention group and comparison group respondents. As such, straightforward comparisons of changes in the outcomes of interest between the two study groups, such as difference-in-difference analysis, did not appear appropriate to estimate program effects. PSM has gained popularity to estimate intervention effects when participants differ between intervention and comparison groups [40]. We thus applied PSM models for estimating intervention effects. The intervention area individuals who did not have individuals with a similar covariate pattern in the comparison area were excluded from the analysis. By contrast, the difference-in-difference analysis does not exclude such individuals. The best possible analysis would have been combining difference-in-difference analysis with PSM models. However, our data did not permit it.

The major limitation of this study is that the ATEs estimated from PSM models do not account for unmeasured confounders and selection bias. For example, if the Government of Ethiopia's ambulance program was significantly better in the intervention areas compared with the comparison areas, then the effects of the intervention on institutional delivery would be an over-estimate. The sampling strategy used for the study can be criticized for introducing bias because the interviewers may avoid hard-to-reach areas and non-responders may not be revisited [35]. Nonetheless, since the sampling bias was similar in the two study arms, and since the intervention effects were the differences in the outcomes of interest between intervention and comparison groups, the sampling bias was likely cancelled out from the intervention effect estimates.

\section{Conclusions}

This study indicates initiatives targeted at improving maternal and neonatal health services appear to work better where community engagement is part of the quality improvement approach. The PCQI strategy is associated with increased service utilization of maternal care services, although their effect on postnatal and neonatal care is less clear. Any quality improvement approaches on maternal and newborn care practices should consider engaging communities to complement their strategies. Further studies could be conducted to assess the determinant factors for successful community engagement in improving quality of care including client confidence, trust and perception towards the health system. Moreover, cost-effectiveness of the PCQI strategy and the effects on postnatal and neonatal care, in addition to a wider set of outcomes, should be explored further.

\section{Additional file}

Additional file 1: Standardized mean differentials of the co-variates between the two study arms, before and after matching. This table shows the standardized differences in the co-variates between intervention and comparison group respondents before and after matching for the seven PSM models. (DOCX $52 \mathrm{~kb}$ )

\section{Abbreviations}

ANC: Antenatal care; ATE: Average treatment effect; BEmONC: Basic emergency obstetric and newborn care; CBDDM: Community-based data for decision-making; Cl: Confidence interval; HEW: Health Extension Worker; L10 K: Last ten kilometers; PCQI: Participatory community quality improvement; PNC: Postnatal care; PSM: Propensity score matching; WDA: Women's development army

\section{Acknowledgements}

Our special thanks go to Josephine Borghi for her invaluable comments throughout the write up process. We thank the Health Extension Workers and Women's Development Army for their contribution towards implementing the intervention. We are also thankful to the women respondents who voluntarily participated in this study, and for the support of the Regional Health Bureaus of Amhara, Oromia, Southern Nations, Nationalities and Peoples' and Tigray regions, and the L10 K implementing partners: Amhara Development Association, Bench Maji Development Association, Ethiopian Kale Hiwot Church, Fayyaa Integrated Development Organization, Illu Women and Children Integrated Development Association, Kaffa Development Association, Oromia Development Association, Relief Society of Tigray, Sheka Peoples' Development Association, Siltie Development Association, Southern Region's Women's Association, and Women's Association of Tigray all of which were critical for the data collection.

\section{Funding}

Funding for the study and for publication was provided by the Bill \& Melinda Gates Foundation.

\section{Availability of data and materials}

The dataset generated and analyzed during the study are available from Ali Karim, one of the co-authors of this manuscript, on reasonable request.

\section{About this supplement}

This article has been published as part of BMC Pregnancy and Childbirth Volume 18 Supplement 1, 2018: Community-based strategies to improve maternal and newborn health in Ethiopia. The full contents of the supplement are available online at https://bmcpregnancychildbirth.biomedcentral.com/ articles/supplements/volume-18-supplement-1.

Authors' contributions

Conceived and designed the experiment: AMK, TW, WB. Performed the experiment: TW, NF, SD, AW, WB. Analyzed the data: AMK. Contributed 
materials/analysis tools: AMK, TW. Wrote the paper: AMK, TW. Contributed to the editing: AB. All authors read and approved the final version of the manuscript.

\section{Ethics approval and consent to participate}

Verbal consent was sought and documented by the interviewers. If the respondent was under 18 years old, then consent was sought from her husband parents or guardian. As it was expected that most of the respondents could not read or write, written consent was not sought. For the 2010-11 survey the ethical approval was obtained from the ethical review committee of the Ethiopian Public Health Association. For the 2014-15 survey the ethical approvals were obtained from the ethical review boards of the regional health bureaus of Amhara, Oromia, Southern Nations, Nationalities and Peoples' Region and Tigray and from the ethical review board of JSI Research \& Training Institute, Inc

\section{Consent for publication}

Not applicable.

\section{Competing interests}

The authors declare that they have no competing interests.

\section{Publisher's Note}

Springer Nature remains neutral with regard to jurisdictional claims in published maps and institutional affiliations.

\section{Author details}

${ }^{1}$ The Last Ten Kilometers Project (L10K) 2020, JSI Research and Training Institute, Inc, Bole Sub-City, Kebele 03/05, Hs \# 2111, Addis Ababa, Ethiopia. ${ }^{2}$ Department of Disease Control, Faculty of Infectious and Tropical Disease, London School of Hygiene and Tropical Medicine, Keppel Street, London WC1E 7HT, UK.

\section{Published: 24 September 2018}

\section{References}

1. World Health Organization. Trends in Maternal Mortality: 1990 to 2015 Estimates by WHO, UNICEF, UNFPA, World Bank Group and the United Nations Population Division 2015. http://www.who.int/reproductivehealth/ publications/monitoring/maternal-mortality-2015/en/. Accessed 21 Jun 2017.

2. World Health Organization. Maternal mortality. 2017. http://www.who.int/ gho/maternal_health/mortality/maternal_mortality_text/en/. Accessed 21 Jun 2017.

3. World Health Organization, UNICEF. Countdown to 2015 Decade Report (2000-2010). 2010. http://www.who.int/pmnch/topics/child/ 2010countdown_decadereport/en/. Accessed 21 June 2017.

4. United Nations. Transforming our world: the 2030 Agenda for Sustainable Development. A/RES/70/1 2015. http://www.un.org/ga/search/view_doc. asp?symbol=A/RES/70/1\&Lang=E. Accessed 21 Jun 2017.

5. Bhutta ZA, Das JK, Bahl R, Lawn JE, Salam RA, Paul VK, et al. Can available interventions end preventable deaths in mothers, newborn babies, and stillbirths, and at what cost? Lancet. 2014;384:347-70.

6. World Health Organization. Strategies toward ending preventable materna mortality (EPMM). Geneva: WHO; 2015. http://who.int/reproductivehealth/ topics/maternal_perinatal/epmm/en/. Accessed 20 Jun 2017

7. The Federal Democratic Republic of Ethiopia Ministry of Health. Health Sector Transformation Plan. Addis Ababa: FMOH; 2015. http://www. globalfinancingfacility.org/sites/gff_new/files/documents/HSTP Ethiopia.pdf. Accessed 20 Jun 2017

8. Fotso JC, Mukiira C. Perceived quality of and access to care among poor urban women in Kenya and their utilization of delivery care: harnessing the potential of private clinics? Health Policy Plan. 2012;27:505-15.

9. Kambala C, Lohmann J, Mazalale J, Brenner S, De Allegri M, Muula AS, et al. How do Malawian women rate the quality of maternal and newborn care? Experiences and perceptions of women in the central and southern regions. BMC Pregnancy Childbirth. 2015; https://doi.org/10.1186/s12884015-0560-x.

10. Karim RM, Abdullah MS, Rahman AM, Alam AM. Identifying influence of perceived quality and satisfaction on the utilization status of the community clinic services; Bangladesh context. Bangladesh Med Res Counc Bull. 2015;41:1-12.
11. Dickson KE, Kinney MV, Moxon SG, Ashton J, Zaka N, Simen-Kapeu A, et al. Scaling up quality care for mothers and newborns around the time of birth: an overview of methods and analyses of intervention-specific bottlenecks and solutions. BMC Pregnancy Childbirth. 2015; https://doi.org/10.1186/ 1471-2393-15-S2-S1.

12. Tunçalp Ö, Were WM, MacLennan C, Oladapo OT, Gülmezoglu AM, Bahl R, et al. Quality of care for pregnant women and newborns-the WHO vision. BJOG. 2015;122:1045-9.

13. Department of Making Pregnancy Safer. World Heal. Organ. World Heal. Organ. working with individuals, families and communities to improve Maternal and newborn health. Geneva: WHO; 2010. http://apps.who.int/iris/ bitstream/10665/84547/3/WHO_MPS_09.04_eng.pdf Accessed 25 Oct 2017

14. Health Organization W. Milestones in health promotion: statements from global conferences. Geneva: World Health Organization; 2009. http://www. who.int/healthpromotion/Milestones_Health_Promotion_05022010.pdf. Accessed 25 Oct 2017

15. Beard TC, Redmond S. DECLARATION OF ALMA-ATA. Lancet. 1979;313:217-8.

16. Reduction of maternal mortality: A joint WHO/UNFPA/UNICEF/World Bank statement. Geneva: WHO; 1999. http://apps.who.int/iris/bitstream/10665/ 42191/1/9241561955_eng.pdf. Accessed 25 Oct 2017.

17. Howard-Grabman L, Miltenburg AS, Marston C, Portela A. Factors affecting effective community participation in maternal and newborn health programme planning, implementation and quality of care interventions. BMC Pregnancy and Childbirth. 2017; https://doi.org/10.1186/s12884-017-1443-0.

18. WHO Regional Office for Europe. Community participation in local health and sustainable development: Approaches and techniques. Geneva: WHO; 2002. http://www.euro.who.int/_data/assets/pdf_file/0013/101065/E78652. pdf. Accessed 25 Oct 2017

19. Morgan MA, Lifshay J. Community engagement in public health. Martinez: Contra Costa Health Services; 2006. http://servingohiobetter.org/site/wpcontent/uploads/2014/08/MessagingTool11.pdf. Accessed 25 Oct 2017

20. Marston C, Hinton R, Kean S, Baral S, Ahuja A, Costello A, Portela A. Community participation for transformative action on women's, children's and adolescents' health. Bull World Health Organ. 2016; https://doi.org/10. 2471/BLT.15.168492.

21. Olayo R, Wafula C, Aseyo E, Loum C, Kaseje D. A quasi-experimental assessment of the effectiveness of the Community Health Strategy on health outcomes in Kenya. BMC Health Serv Res. 2014;14:(Suppl 1)S3. https://doi.org/10.1186/1472-6963-14-S1-S3. Epub 2014 May 12.

22. Sibley LM, Tesfaye S, Fekadu Desta B, Hailemichael Frew A, Kebede A, Mohammed $\mathrm{H}$, et al. Improving Maternal and Newborn Health Care Delivery in Rural Amhara and Oromiya Regions of Ethiopia Through the Maternal and Newborn Health in Ethiopia Partnership. J. Midwifery \& Women's Heal. 2014;59 https://doi.org/10.1111/jmwh.12147.

23. Marston C, Renedo A, Mcgowan CR, Portela A, Braitstein P. Effects of community participation on improving uptake of skilled care for maternal and newborn health: a systematic review. PLoS One. 2013; https://doi.org/ 10.1371/journal.pone.0055012.

24. Rosato M, Laverack G, Grabman LH, Tripathy P, Nair N, Mwansambo C, et al. Alma-Ata: rebirth and revision 5 community participation: lessons for maternal, newborn, and child health. Lancet. 2008; https://doi.org/10.1016/ s0140-6736(08)61406-3.

25. Alhassan RK, Nketiah-Amponsah E, Arhinful DK. Design and implementation of community engagement interventions towards healthcare quality improvement in Ghana: a methodological approach. Health Econ Rev. 2016; https://doi.org/10.1186/s13561-016-0128-0.

26. Rifkin SB. Examining the links between community participation and health outcomes: a review of the literature. Health Policy Plan. 2014; https://doi. org/10.1093/heapol/czu076. Oxford University Press

27. Rifkin SB. Lessons from community participation in health programmes: a review of the post Alma-Ata experience. Int Health. 2009; https://doi.org/10. 1016/j.inhe.2009.02.001.

28. Damtew ZA, Karim AM, Willey B, Tesfaye C, Fesseha Zemichael N, Yeshanew B, et al. Correlates of the Women's Development Army strategy implementation strength with household reproductive, maternal, newborn and child healthcare practices: a cross-sectional study in four regions of Ethiopia. BMC Pregnancy Childbirth. 2018;18(Suppl 1). https://doi.org/10.1186/s12884-018-1975-y.

29. Central Statistical Agency (CSA) [Ethiopia], ICF. Ethiopia Demographic and Health Survey 2016: Key indicators report. Addis Ababa and Rockville: CSA and ICF; 2016. http://wwwethiodemographyandhealthorg/Ethiopia_DHS 2016_KIR_-_Final_10-17-2016pdf Accesssed 27 October 2017 
30. Ageze L. Health Facility Governance in the Ethiopian Health System. Bethesda: Health Systems 20/20; 2012. https:/www.hfgproject.org/wpcontent/uploads/2015/02/Health-Facility-Governance-in-the-EthiopianHealth-System.pdf. Accessed 27 Oct 2017

31. Federal Democratic Republic of Ethiopia Ministry of Health (FMOH). Health Extension Program Implementation Guideline (Revised). Addis Ababa: $\mathrm{FMOH} ; 2012$.

32. Karim AM, Fesseha Zemichael N, Shigute T, Emaway Altaye D, Dagnew $S$, Solomon F, et al. Effects of a community-based data for decision-making intervention on maternal and newborn health care practices in Ethiopia: a dose-response study. BMC Pregnancy Childbirth. 2018;18(Suppl 1). https:// doi.org/10.1186/s12884-018-1976-X.

33. Emaway Altaye D, Karim AM, Betemariam W, Fesseha Zemichael N, Shigute T, Scheelbeek P. Effects of family conversation on health care practices in Ethiopia: a propensity score matched analysis. BMC Pregnancy Childbirth. 2018; 18(Suppl 1). https://doi.org/10.1186/s12884-018-1978-8.

34. UNICEF. Ethiopia - maternal health brief [No date]. https://www.unicef.org/ ethiopia/UNICEF_Flier_2.pdf. Accessed 28 Oct 2017.

35. Lemeshow S, Robinson D. Surveys to measure programme coverage and impact: a review of the methodology used by the expanded programme on immunization. World Heal Stat Q. 1985;38:115-32.

36. Filmer DPL. Estimating wealth effects without expenditure data—or tears: an application to educational enrollment in states of India. Demography. 2001;38:115-32.

37. StataCorp. Stata: Release 14. Statistical Software. College Station: StataCorp LP; 2015.

38. StataCorp. Stata Treatment-Effects Reference Manual: Potential Outcomes/ Counterfactual Outcomes, Release 14. College Station: StataCorp LP; 2015.

39. Stuart EA, Rubin DB. Best practices in quasiexperimental designs: matching methods for causal inference. In: Osborne J, editor. Best practices in quantitative methods. Thousand Oaks: Sage Publications; 2008. p. 155-76.

40. Austin PC. Balance diagnostics for comparing the distribution of baseline covariates between treatment groups in propensity-score matched samples. Stat Med. 2009;28:3083-107.

41. Holmes W, Goldstein M. "Being treated like a human being": attitudes and behaviours of reproductive and maternal health care providers. 2012. https://www.burnet.edu.au/system/asset/file/1408/Holmes_et_al_attitudes review_sept2_final.pdf. Accessed 30 Oct 2017.

42. Mannava P, Durrant K, Fisher J, Chersich M, Luchters S. Attitudes and behaviours of maternal health care providers in interactions with clients: a systematic review. Glob Health. 2012; https://doi.org/10.1186/s12992-0150117-9.

43. Owor MO, Matovu JKB, Murokora D, Wanyenze RK, Waiswa P. Factors associated with adoption of beneficial newborn care practices in rural eastern Uganda: a cross-sectional study. BMC Pregnancy Childbirth. 2016;16: 83. https://doi.org/10.1186/s12884-016-0874-3.

44. Gurung G. Practices on immediate care of newborn in the communities of Kailali district. Nepal Med Coll J. 2008;10(1):41-4.

45. Hill Z, Tawiah-Agyemang C, Manu A, Okyere E, Kirkwood BR. Keeping newborns warm: beliefs, practices and potential for behaviour change in rural Ghana. Trop Med Int Heal. 2010;15:1118-24.

Ready to submit your research? Choose BMC and benefit from:

- fast, convenient online submission

- thorough peer review by experienced researchers in your field

- rapid publication on acceptance

- support for research data, including large and complex data types

- gold Open Access which fosters wider collaboration and increased citations

- maximum visibility for your research: over $100 \mathrm{M}$ website views per year

At BMC, research is always in progress.

Learn more biomedcentral.com/submissions 